\title{
EVALUATING LOCAL SUSTAINABILITY: PLANNING IN NORTHERN BRITISH COLUMBIA, CANADA
}

\author{
J.A. CURRY ${ }^{1} \&$ I.M. PICKETTS ${ }^{2}$ \\ ${ }^{1}$ School of Environmental Planning, University of Northern British Columbia, Canada. \\ ${ }^{2}$ Ecosystem Sciences and Management, University of Northern British Columbia, Canada.
}

\begin{abstract}
Local governments in British Columbia have been presented with an opportunity to become more sustainable through the development of Integrated Community Sustainability Plans (ICSPs). These are broad overarching documents aimed at guiding all community decision making towards environment, social, and economic sustainability. This article explores these planning efforts, focusing on the development of the City of Prince George ICSP. Ten key dimensions for sustainable city development developed by Jeffrey Kenworthy are used as evaluative criteria to explore the effectiveness of the Prince George ICSP in promoting the complex topic of sustainability to residents and decision makers. An 11th criterion, related to climate change, is also added to Kenworthy's dimensions. The results of this evaluative research show positive activities in moving towards mixed-use and compact development; integrating natural elements into the urban landscape; developing a communication plan which engages and educates the public; and considering local and regional climate change impacts. Attention needs to be focused towards improving multimodal transportation development and creating a more high-quality public realm. Using Kenworthy's dimensions to evaluate the plans has proven to be a worthwhile exercise revealing sustainability strengths and weaknesses. As sustainability planning is relatively new in northern cities and towns, this assessment will help other northern and rural communities to guide their own plans.
\end{abstract}

Keywords: Climate change, environmental planning, evaluative criteria, local government, municipal planning, sustainability.

\section{INTRODUCTION}

In 2005, the governments of Canada and British Columbia, along with the Union of British Columbia municipalities, finalized a Gas Tax Agreement which created the Integrated Community Sustainability Planning (ICSP) Initiative. This initiative allows for provincial government interests in sustainability, integrated decision making, and action on climate change to be supported by municipalities through funding for local and regional-level plans [1]. Most communities in BC have now completed ICSPs, and the City of Prince George completed its ICSP initiative (entitled 'myPG') in 2010. The purpose of this article is to assess the effectiveness of the myPG plan in moving Prince George towards a higher state of sustainability by using Jeffrey Kenworthy's 10 dimensions for sustainable city development [2] as evaluative criteria. Kenworthy developed these dimensions, drawing on his extensive research in transportation planning and sustainability through evaluative research of world cities over the past quarter century. This research adds to the literature by exploring local-scale sustainability within a Canadian and northern context. The article strengthens and adds to Kenworthy's 10 dimensions for sustainable city development, sets a framework for evaluating ICSPs, assesses the effectiveness of the evaluation process, and suggests recommendations for improvements to ICSP planning in Prince George and Canada.

Prince George is a city of 76,000 situated near the centre of Province of British Columbia (BC) (Fig. 1) [3]. The City is located at the cross-roads of northern BC and is a central node in a multimodal transportation network, accessing export markets by road, air, and rail (and also navigable waters). Significant growth took place in the City during the 1960s and 1970s when small regional 


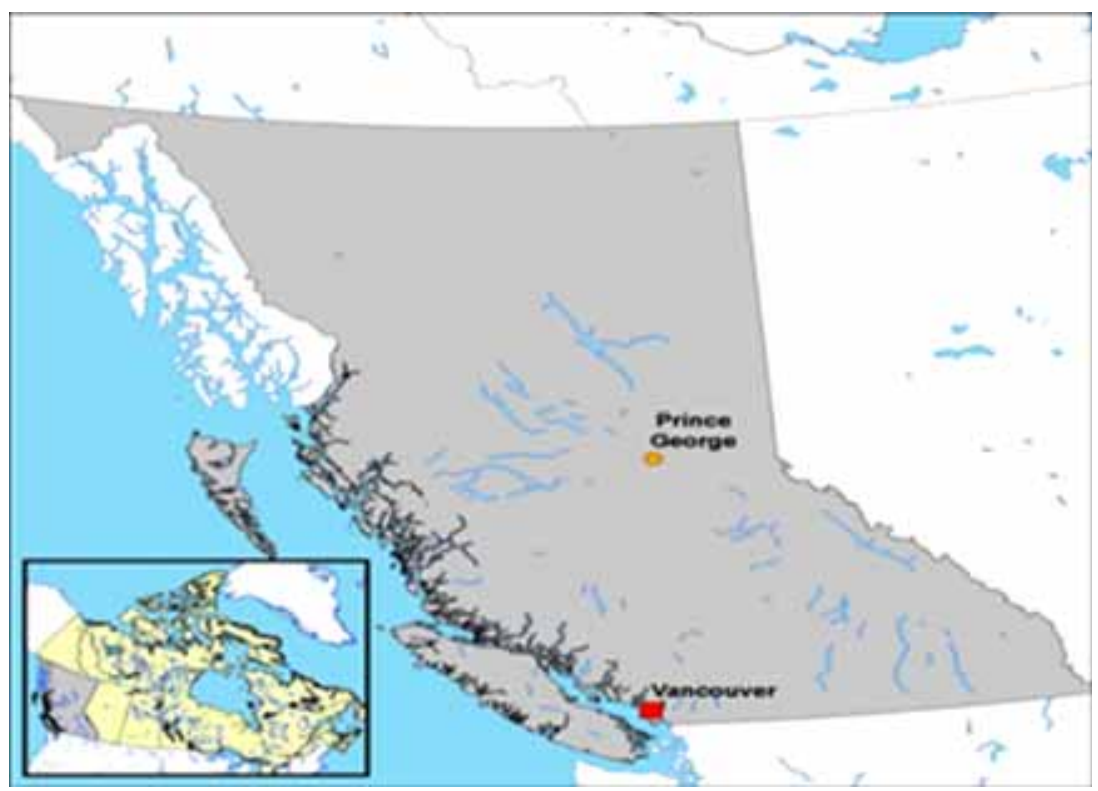

Figure 1: Locator map of Prince George within Canada.

forest products enterprises consolidated into large processing and manufacturing operations. During this period of rapid growth, low-density development with large lot sizes dominated, resulting in significant sprawl with a heavy dependence on the automobile to move across the urban landscape [4]. Prince George is traditionally a logging town and still has a large dependence on the forest sector for economic activity. The City is trying to capitalize on its geographical location and become a hub for trade between Western Canada and Asian markets. The emergence of Asian markets and the faltering U.S. economy has led to an increased emphasis on Asia as a future trading partner. Prince George struggles to balance its dependence on resource development for economic activity and maintain a strong community in which residents can access outdoor recreational activities and appreciate a connection with nature. Many local governments in BC (and around the world) struggle to reconcile their reliance on extracting and exporting natural resources for economic growth, and local interests in environmental and social sustainability. The development of an ICSP presents an ideal opportunity to begin addressing the challenges of balancing growth, trading opportunities, environmental health, and community connections in Prince George.

There have been many local, regional, and global changes which are affecting Prince George and northern British Columbia. Climate change is occurring more rapidly in northern regions, and its impacts have dramatically changed the face of the region. For example, the mountain pine beetle (Dendroctonus ponderosae) is a natural forest pest whose populations are typically controlled by extremely cold winter conditions [5]. Winter temperatures are rising especially fast in north-central BC [5] and the pine beetle outbreak has reached an unprecedented level, impacting over $130,000 \mathrm{~km}^{2}$ of forests [6]. Other major climate-related impacts in Prince George include increased flooding, greater incidences of extreme weather, and impacts to transportation infrastructure [7]. 


\section{THE SUSTAINABILITY CHALLENGE}

Sustainable development and its cognate, sustainability, have been reflected in urban planning in a variety of ways, including Healthy Communities [8], urban design (New Urbanism), land use planning, and Smart Growth [9-12]. In 1987, the World Commission on Environment and Development (Bruntland Commission) focused the world's attention to the issue of sustainable development. Since then a number of common themes and requirements for sustainability have emerged from the literature. Some of the requirements that have emerged are as follows.

In 1989, Milbrath [13] identified five requirements for sustainability. These were:

1. Preserving and enhancing a well-functioning ecosystem;

2. Providing humans with goods and services sufficient for a 'good life';

3. Providing opportunities for fulfilling work;

4. Achieving and maintaining economic justice; and

5. Not exhausting resources faster than they can be replenished.

In 1992, the Rio Declaration on Environment and Development presented a list of 27 sustainability principles related to human rights, equality, global cooperation, ecological protection, and environmental health [14]. In 1996 the International Institute for Sustainable Development hosted a conference, which resulted in the development of the 10 Bellagio Principles [15] to assess progress towards sustainable development. Principles included practicality, openness, inclusiveness, capacity building, and ongoing effectiveness evaluation. To evaluate a subset of environmental plans, in 2000, Berke and Conroy [16] posited six basic principles of sustainability. These were harmony with nature, liveable built environments, place-based economy, equity, polluters pay, and respectable regionalism.

As lists of sustainability principles were developed and refined, principle subsets evolved specifically for different elements of the society. In the area of urban and regional planning, the 2006 World Planners Congress developed the Vancouver Declaration [17]. Conference participants representing a large number of the professional planning organizations around the world stated, 'We assert that there can be no sustainable development without sustainable urbanization and no sustainable urbanization without effective planning: political will and investment is required for effective planning' [18].

The principles and declarations above showcase recent progress in the idea of sustainability and aided the authors in exploring the development of principles to support community sustainability. However, we felt that each of these sets of principles were too broad to give course of action to planners and other local practitioners. Many of the principles (i.e. polluter pay, or not exhausting resources faster than they can be replenished) go beyond the realistic scope of a community plan within a Canadian context. They cannot be used to effectively provide direction to planning towards sustainability or implementing concepts of local sustainability in regions of the world that are already highly developed.

After a further review of the sustainability principles literature, we determined that the most straightforward and applicable list of requirements for a sustainable community to benchmark a sustainability plan for a local government in a northern community has been developed by Jeffrey Kenworthy. These requirements align with the principles discussed above and also with the stated purpose of the myPG Integrated Community Sustainable Plan. From an urban planning perspective (see Table 1), Kenworthy presents definitive principles, which can guide practical movements towards sustainability, set the framework for evaluating implementation effectiveness over time, and provide the basis for the development of measurable, local-level community sustainability 
Table 1: Kenworthy's dimensions for sustainable city development.

1. The city has compact, mixed-use urban form that uses land efficiently and protects the natural environment, biodiversity, and food-producing areas.

2. The natural environment permeates the city's spaces and embraces the city, while the city and its hinterland provide a major proportion of its food needs.

3. Freeway and road infrastructure is de-emphasized in favour of transit, walking, and cycling infrastructure with a special emphasis on rail. Automobile use is minimized.

4. There is extensive use of environmental technologies for water, energy, and waste management - the city's life support systems become closed-loop systems which produce resources rather than waste.

5. The central city centres and sub-centres are human centres that emphasize access and circulation by modes of transport other than the automobile and absorb a high proportion of employment and residential growth.

6. The city has a high-quality public realm throughout that expresses a public culture, community, equity, and good governance. The public realm includes the entire transit system and all the environments associated with it.

7. The physical structure and urban design of the city, especially its public environments, are highly legible, permeable, robust, varied, rich and visually appropriate, and personalized for human needs.

8. The economic performance of the city and employment creation are maximized through innovation, creativity and uniqueness of the local environment, culture and history, as well as the high environmental and social quality of the city's public environments.

9. Planning for the future of the city is a visionary 'debate and decide process' not a 'predict and provide', computer-driven process.

10. All decision making is sustainability based, integrating social, economic, environmental, and cultural considerations as well as compact, transit-oriented urban form principles. Such decision-making processes are democratic, inclusive, empowering, and engendering of hope.

Additional dimension:

11. Climate change is integrated into all aspect of local-level planning, and there is commitment to addressing climate change through the processes of adaptation and mitigation.

Source: Adapted from Ref. [2].

indicators. The criteria are presented below in Table 1 along with one additional dimension added, highlighting the importance of climate change in both the geographical region and the broader movement towards community and regional sustainability. This is not an exhaustive or complete list and it does not reflect the entire breadth of the term sustainability. Kenworthy himself notes ' $[\mathrm{t}] \mathrm{h}$ ese ten dimensions are not comprehensive', excluding topics such as poverty, political power structures, and community decision-making processes. They do focus on 'transport, planning and designoriented dimensions of sustainable city development' [19].

\section{METHODOLOGY}

Case studies are important forms of empirical research that can lead to an in-depth understanding of elements of the real world [20,21]. An exploratory, holistic, evaluative case study design was used to test the effectiveness of ICSPs with the City of Prince George representing the case study area. The 


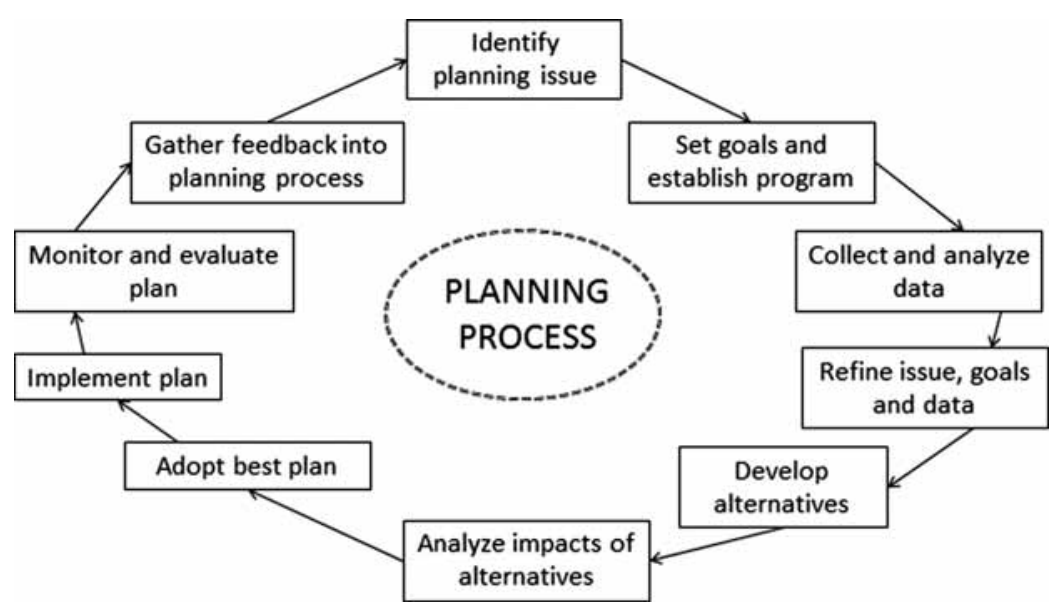

Figure 2: Planning process (Model adapted from the rational planning model [23]).

decision to use a case study inquiry method was influenced by a number of considerations. As Yin [20] notes, the case study method is ideally suited for studying the complexity of organizational phenomena, specifically, in studying a planning process and a final plan document.

As Patton defines' $[\mathrm{e}]$ valuative research . . . can include any effort to judge or enhance human effectiveness through systematic data-based inquiry.' [22] Summative evaluation is the research method used to explore the effectiveness of plans or programs. Summative evaluation methods are used to assess the application of a plan to bring about societal change, in this case to explore how to identify ways to improve the effectiveness of the Prince George ICSP using Kenworthy's 10 dimensions for Sustainable City Development as evaluative criteria. The research questions for this study are as given below:

1. 'Using Kenworthy's dimensions as comparative criteria, what are the strengths and weaknesses of the myPG plan in moving towards community sustainability?'

2. 'How can the Prince George ICSP be improved to better reflect Kenworthy's dimensions?'

3. 'Are Kenworthy's dimensions appropriate for evaluating community sustainability planning in developed regions?'

Evaluation plays an important role in urban and regional planning processes. Figure 2 represents an iterative, recursive planning process, which typically begins with identifying a planning issue and defines goals and a work plan, and progresses towards monitoring and evaluating the adopted plan, which provides feedback to improve the planning intervention. The planning process is recursive if evaluation techniques are used to improve the planning intervention. The process is iterative as one can enter, or cycle back to earlier stages, in the process to improve the quality of planning.

\section{EVALUATIVE ANALYSIS}

This evaluative analysis does not explore the current level of community sustainability in the City of Prince George. As noted earlier, the City is currently in a state of un-sustainability. This analysis explores the current willingness of the citizens, elected officials, and municipal employees (as represented in their ICSP) to move towards sustainability. Community sustainability literature is readily 
available to city consultants, planning staff, educational institutions, and other planning-oriented professions. The 10 key dimensions for Sustainable City Development compiled by Kenworthy [19], and the additional dimension, are used as the evaluative criteria to explore the degree of sustainability of the Prince George ICSP (myPG) [24].

The results of this evaluative analysis will test the effectiveness of both the myPG plan and the evaluation technique. The framework outlined will illustrate how other integrated community sustainability plans can be evaluated and, over time, tracked to determine how effectively they are being implemented.

Most attempts to evaluate the quality or effectiveness of plans aim to assign scores to attributes of the plan that link to principles or criteria $[16,17,25]$. The scores are typically numerical and based on factors such as numbers of examples, strengths of associations, levels of details, and nearness of language $[16,26]$. While the results of these exercises provide valuable quantitative outputs, we felt that this approach unduly simplifies the depth of sustainability, the interactions between principles, and the ability for a sustainability plan to actually advance and enhance (or detract from) a principle. Also, as the research is somewhat exploratory and focused on a more northern community, there is value in openly discussing the attributes of the plan as compared to Kenworthy's principles. However, it is also important to have consistent evaluation criteria. Therefore, we have outlined qualitative 'assessment of support' criteria to be used for evaluating each Kenworthy dimension (Table 2), which are similar to those developed by Baker et al. [25]:

Each principle was independently assessed by the authors and revisited if there was a discrepancy in the assessment. In no cases did the assessment differ by more than one ranking. Each of Kenworthy's dimensions, and the 11th dimension, are discussed and assessed in turn below and summarized in Tables 3 and 4.

\subsection{Compact and mixed-use urban form}

In the review of the myPG sustainability plan, the following information was identified which is related to the main elements of Kenworthy's first dimension (Table 1). The myPG plan deals with

Table 2: Criteria for evaluating the ICSP as it relates to Kenworthy's criteria.

\begin{tabular}{ll}
\hline Assessment of support & \multicolumn{1}{c}{ Rationale } \\
\hline $\begin{array}{l}\text { Excellent to } \\
\text { exemplary }\end{array}$ & $\begin{array}{l}\text { Multiple references to the principle throughout many sections of } \\
\text { the Plan. Language from principle is strongly reflected in the Plan } \\
\text { (excellent), or language builds upon principle (exemplary). } \\
\text { References to principle throughout the Plan. Language from principle } \\
\text { is strongly reflected in the Plan (very good), or language is reflected but } \\
\text { with a more permissive tone (good). } \\
\text { At least one direct or multiple indirect references in the plan. Language } \\
\text { may be permissive or not directly reflective of principle, and some } \\
\text { contradictory statements may exists. } \\
\text { One or more references in the plan that vaguely support the principle, } \\
\text { and contradictory statements. } \\
\text { No references in plan that support principle (no support), or references } \\
\text { that actively detract from or oppose the principle (unsupport). }\end{array}$ \\
$\begin{array}{l}\text { Inadequate } \\
\text { unsupport }\end{array}$ &
\end{tabular}


Table 3: Kenworthy's dimensions where Prince George is performing well.

\begin{tabular}{|c|c|c|}
\hline Dimension & $\begin{array}{c}\text { Assessment } \\
\text { of support }\end{array}$ & Description \\
\hline $\begin{array}{l}\text { Compact and } \\
\text { mixed-use urban } \\
\text { form }\end{array}$ & Very Good & $\begin{array}{l}\text { The City has undertaken significant special area and city- } \\
\text { wide planning processes [27], supporting and encouraging } \\
\text { densification of the urban landscape. }\end{array}$ \\
\hline $\begin{array}{l}\text { Natural environment } \\
\text { permeates the city } \\
\text { spaces }\end{array}$ & Excellent & $\begin{array}{l}\text { The myPG plan addresses the City's location within a } \\
\text { vast rural natural landscape. Future urban redevelopment } \\
\text { opportunities may maintain and further integrate nature } \\
\text { into the city. }\end{array}$ \\
\hline $\begin{array}{l}\text { Centre city and } \\
\text { sub-centres are } \\
\text { human centres }\end{array}$ & Adequate & $\begin{array}{l}\text { The myPG plan supports continuing efforts to revitalize the } \\
\text { downtown as the social, cultural, and business centre of the } \\
\text { community. }\end{array}$ \\
\hline $\begin{array}{l}\text { Economic } \\
\text { performance } \\
\text { maximized }\end{array}$ & Adequate & $\begin{array}{l}\text { The integration of, and willing involvement of, economic } \\
\text { development agencies in the sustainability planning } \\
\text { process is very positive. This, potentially, will encourage } \\
\text { buy-in from the business community and allow a smooth } \\
\text { transition towards implementation. }\end{array}$ \\
\hline $\begin{array}{l}\text { Planning for the } \\
\text { future is 'debate and } \\
\text { decide' not 'predict } \\
\text { and provide' }\end{array}$ & Excellent & $\begin{array}{l}\text { The City recognized that an effective communication plan } \\
\text { which engages, informs, and educates community residents } \\
\text { will play a key role in the movement towards sustainability. } \\
\text { The City put forth an exceptional effort to engage residents } \\
\text { in the myPG process. }\end{array}$ \\
\hline $\begin{array}{l}\text { Climate change is } \\
\text { integrated into all } \\
\text { aspects on the } \\
\text { local-level planning }\end{array}$ & Very Good & $\begin{array}{l}\text { The myPG plan highlights numerous current and proposed } \\
\text { climate change initiatives addressing both mitigation } \\
\text { and adaptation, and stresses the need to integrate } \\
\text { climate change considerations in long-range planning } \\
\text { processes. Climate change is a relatively new dimension } \\
\text { of community planning and, therefore, the city should } \\
\text { be applauded for incorporating related measures in the } \\
\text { myPG plan. }\end{array}$ \\
\hline $\begin{array}{l}\text { Multimodal } \\
\text { transportation }\end{array}$ & Good & $\begin{array}{l}\text { The myPG plan is calling for appropriate actions to move } \\
\text { the transportation system to a higher state of sustainability. } \\
\text { The existing sprawling built landscape persists as the most } \\
\text { significant issue in moving towards a sustainable future. } \\
\text { Therefore, possibly the greatest achievement of the myPG } \\
\text { planning process could be the reversal of this trend. }\end{array}$ \\
\hline
\end{tabular}

compact urban landscapes in a number of plan sections. An ancillary or special area plan is the Smart Growth on the Ground (SGOG) Downtown Concept Plan [28]. The SGOG plan 'envisions a civic and cultural centre of the city with major green spaces, a healthy and supportive community, and a reasonably high density mix of people and activities' [24]. There is also a desire to construct a mixed-use green building downtown which will act as a demonstration project and information centre highlighting information on sustainable business and living [28]. Green building practices and design are perceived as one method to protect the natural environment [24]. 
Table 4: Kenworthy's dimensions where Prince George is not performing well, and suggestions for improvement.

High-quality public Inadequate realm and human-scale quality public realm
Few statements in the plan support a higher quality (or more human scale) public realm. The lack of previous acknowledgement of the importance of urban design is likely the primary reason for these missing dimensions in the myPG plan. Hiring urban design professionals, incorporating winter city design elements, and incorporating property landscape design into the development and redevelopment process will enhance this important element of city building.

Physical structure and Inadequate public environments appropriate for human needs

Decision making is Inadequate sustainability based
The myPG plan provides almost no direction on the design of the urban landscape. The same actions noted immediately above for urban design can alleviate this shortcoming.

The lack of references to integrating sustainability into community decision making is a final shortcoming in the myPG plan. This may be explained by the relative newness of the topic. Once planning processes are in place, there is a need for decision-making governance processes to incorporate sustainability as one of the standard considerations.

The City is attempting to develop a downtown precinct which will support district heating initiatives through land use changes and higher property densities [24]. These efforts are widespread and include infill development on vacant lands, redevelopment opportunities in the urban area [24], and permitting 'low-density development ( $>4$ acre lots) in the Prince George fringe, provided it is not to the detriment of nearby farm areas' [24]. The majority of information in the myPG plan supports this dimension of community sustainability; therefore, it is assessed as 'very good.'

\subsection{Natural environment permeates city spaces}

The following relevant information to this dimension was noted in a review of the myPG sustainability plan. In opening statements, the myPG plan not only recognizes human dependence on the natural environment but also acknowledges the need to not only protect but also restore nature 'in order to thrive and survive' [24]. One of the plan goals is to 'be a green city with healthy habitat and forests and a strong environmental consciousness, led by local government and local organizations that demonstrate sustainable practices' [24]. A second goal of the plan is to revitalize and connect the downtown 'to its rivers and natural surroundings' [24]. Other methods proposed to allow nature to permeate the urban landscape include increasing 'trails and green space to enhance connectivity and nature throughout the city' [24] and linking 'park and open spaces through greenway corridors and trail development' [24]. The City, although endowed with a large amount of parkland (both on a total area and per capita basis), plans to 'acquire and develop park and open spaces in locations which enhance the overall livability and build upon the valued environmental and cultural resources of the community' [24]. 
Prince George has addressed this dimension of city sustainability at a level that can be considered 'excellent'. The community is fortunate that it is still relatively small with natural landscapes within and surrounding the city. Watercourses, although impacted by environmental degradation, are in the process of being rehabilitated, and the low development density creates large spaces between buildings, permitting the integration of nature into the urban landscape.

\subsection{Multimodal transportation}

The myPG plan calls for the City to 'shift budgets to prioritize investment in walking, cycling, and transit over new investment in vehicle-focused infrastructure' [24]. The objective is to 'create a transit network with frequent, direct, reliable service on key corridors between neighbourhood centres' [24]. The City of Prince George Trail System Master Plan [29] proposes a trail system consisting of 'a series of connected loops, allowing users to move easily around the city on a trail rather than a road or road edge' [24] and the Active Transportation Plan 'sets the stage to develop, enhance, and implement models of active transportation to promote health, quality of life, and economic development, while reducing negative environmental impacts' [30]. The SGOG Downtown Concept Plan [28] encompasses many of the above-mentioned transportation modes including 'walking/ cycling/transit, along green, high amenity streets and greenways' [24].

The City desires to partner with the private sector and other institutional employers in developing 'new high profile Transportation Demand Management programs' [24] which will 'employ incentives to increase use of transit, walking and cycling' [24].

The myPG plan is encouraging the appropriate actions to move the transportation system to a higher state of sustainability. Unfortunately, the land use legacy (outlined in Section 4.1) of Prince George supports continued sprawl in many future land development activities, including big box retail and large lot urban fringe residential development. This inseparable relationship between land use and transportation needs to be further explored by the City, with automobile-dependent urban fringe land developments being highly discouraged or discontinued altogether. The information in the myPG plan supports a 'good' assessment of dimension of community sustainability.

\subsection{Extensive use of environmental technologies}

The myPG plan recommends that Prince George investigate the potential for a district energy system [24] (which has since been constructed); notes the City's initiative in the use of microturbines at the wastewater treatment plant which convert methane gas into heat and power; and highlights the use of wood waste and pulping residue for the production of power to heat saw mills, pulp plants and residential homes [24]. The plan also states the desire to 'invest in local green technology companies' [24] and supports the continuing actions of the Innovation Resource Centre to work with the business community to commercialize innovative technology' [24].

More research and action is needed in this area to develop closed-loop infrastructure that returns resources into the urban system rather than treating and discarding these resources into natural systems.

\subsection{City centre and sub-centres are human centres}

The current population of Prince George can support only one city centre and no sub-centres. Therefore, within the context of Prince George, the goal of this dimension is to emphasize transportation modes (other than the automobile) to the city centre and ensure significant residential growth and employment growth is channeled into the heart of the city. 
The myPG plan observes that 'a vibrant downtown, great community, affordable lifestyle, and spectacular natural setting are Prince George's greatest strengths' [24]. The Plan goes on to state the 'downtown is in need of revitalization' [24], which is contradictory. One of the myPG goals is to 'have a clear identity that the community can be proud of, with a strong downtown and connection to its rivers and natural surroundings' [24]. The purpose of the identified Downtown Partnership is to concentrate its revitalization efforts 'on marketing, redevelopment, safety, and cleanliness' [25]. There is a need to "change perceptions of safety downtown by researching both data and perception, and communicating improvements in clear terms' [25]. The SGOG Downtown Concept Plan 'envisions a civic and cultural centre of the city, with major green spaces, a healthy and supportive community and a reasonably high density mix of people and activities' [25].

There is a strong and continuing interest in revitalizing the downtown as the social, cultural, and business centre of the community. Although the relatively small size of Prince George precludes true nodal development, the myPG plan supports centralization efforts and effectively addresses Kenworthy's dimension of a sustainable city. (It is important to note that the spatial layout of Prince George is of very low density. Therefore, although the myPG plan indicates a move towards nodal development and the City continues to experience high levels of sprawl, this dimension of community sustainability is assessed as 'very good'.

\subsection{High-quality public realm}

The myPG plan calls for the improvement of 'roads and public spaces for a more functional and visually attractive city' [24]. Winter city design (i.e. designs that prepare for and embrace snow and cold weather) is considered an important element of the overall layout of the public realm in Prince George. Pressman [31] notes an important element of northern community planning is incorporating Winter City Design, which is often overlooked. Most plan concepts depict summer scenes and ignore the realities of winter, which in a northern community needs more attention in design plans. A review of the myPG plan document reveals a total of 87 photos, of which 64 are outdoor scenes and only five depict winter: reinforcing the low acknowledgement of multi-seasonality. The City stresses a need to 'draw people to the riverfronts by bringing various public uses close to the rivers' [24] and to 'provide public access and viewpoints to rivers, small watercourses, lakes, and wetlands' [24]. Finally, the myPG plan would like the community to 'develop and maintain parks and open spaces in a manner to create a 'beautiful' and pleasing urban environment' [24]. Significant improvements are needed in addressing the urban design in Prince George, particularly the inclusion of multi-seasonality in the design process [31]. Therefore this dimension is 'inadequately' addressed in the myPG plan.

\subsection{Physical structure and public environments appropriate for human needs}

This dimension is very similar to that discussed in section 4.6 (high-quality public realm). The authors originally contemplated combining these dimensions but elected to maintain the integrity of Kenworthy's original 10 dimensions. The myPG plan makes one reference, discussing the need to 'create shared community spaces within neighborhoods that encourage people to gather, such as open spaces and community centres' [24].

As in the previous section, very little discussion is centered on the design elements of the urban landscape. There are significantly fewer statements in the plan supporting a high-quality public realm and a human-scale public realm than any other dimensions. There is a strong need to more fully explore urban design and planning to appropriately meet this dimension of a sustainable city. Therefore, this dimension is 'inadequately' addressed. 
4.8 Economic performance maximized through innovation, creativity, and uniqueness of local environment

The importance of culture in economic development is acknowledged in the myPG plan in the recommendation, 'have a rich cultural life, with more events, facilities, education, and community involvement in the arts to support economic and social growth' [24]. Other recommendations include being 'a model for northern cities in green and local business, and bioenergy' [24] and 'increase the regional use of alternative energy systems in order to provide overall economic, social, and environmental benefits' [24]. Prince George is also a member of the Creative City Network (an international organization, supported by UNESCO, which promotes local and regional cultural diversity through support to the arts, heritage conservation and other culturally enhancing activities) [24].

Numerous federal, provincial, and local-level organizations support innovation and creativity. The local economic development corporation, Initiatives Prince George, is assisting in the expansion of the City's bioenergy, transportation, and logistics sectors [24]. Economic development has traditionally received significantly more resources than social and environmental development issues. The support for economic development activities continues with the myPG plan, which recognizes the need to integrate other elements of community activities (social cultural, environmental, health, etc.). These initiatives move the community towards a higher state of sustainability and, thus, 'adequately' fulfils Kenworthy's dimension.

\subsection{Planning for the future is 'debate and decide' not 'predict and provide'}

Kenworthy supports human interaction through public participation processes in the exploration of the future rather than computer-driven, human-devoid processes.

The myPG plan 'captures the results of extensive public and stakeholder engagement aimed to create a vision of the long-term future of Prince George and to outline what we need to do now to achieve the vision. It is the first step in the long-term "myPG" process of becoming a sustainable community' [24]. All segments of the community were engaged in the public participation process, including over 2,000 people contributing to a sustainability survey and approximately 250 stakeholders participating in a series of workshops. In addition, traditionally hard-to-reach groups (such as First Nations and developers) were approached to ensure that all facets of the community contributed to the planning process [24]. City staff and consultants ensured that 'all public engagement activities and communications are accessible (re: literacy, language, and medium)' [24]. To ensure continuity after plan completion, the planning staff strove to 'build community association capacity to champion initiatives that provide opportunities for the engagement of all neighbourhood members' [24].

Possibly, the greatest legacy of the myPG process was the efforts to involve and include the community in the planning process and to build citizen capacity to continue to explore sustainability initiatives. Therefore, the myPG plan does an 'excellent' job of fulfilling this dimension

\subsection{Decision making is sustainability based}

The myPG plan 'strategy is to continue to engage the community significantly in decision-making' [24] and to 'continuously test new methods to communicate with and engage residents in community decision-making' [24].

As illustrated by the brief statements in the myPG plan, sustainability decision making was not extensively discussed. Plans can only be implemented through action and action takes place by 
incorporating sustainability issues into day-to-day decision making at all levels of an organization. Kenworthy's dimension is marginally addressed in the myPG and, therefore, would receive 'inadequate' assessment.

\subsection{Climate change is integrated into all aspects on local-level planning}

The final dimension is added to Kenworthy's dimensions by the authors as an important element of sustainability planning. Prince George exhibits a high level of interest in planning for climate change through the processes of adaptation and mitigation. The authors are undertaking further research on climate change adaptation in Prince George [32], and British Columbia is taking a leadership role in climate change mitigation through a provincial carbon tax, which was introduced in 2008 and increases annually [33], and by requiring communities to incorporate greenhouse gas reduction targets into their Official Community Plans.

One of the goals of the myPG plan is to 'reduce carbon emissions and adapt to climate change' [24]. In preparing for climate change, the myPG plan proposes to 'continue to plan for and implement actions to minimize flooding, forest fires and other climate related impacts' [24]. The City will continue efforts in research and implementation in climate mitigation and adaptation; partner with other levels of government and the business community to reduce carbon emissions in a costeffective way; support higher density, compact development in areas adjacent to the downtown and in neighbourhood centres; support this compact development with a nodal and corridor transit system; facilitate a public dialogue about ways to address local and regional climate change impacts; and 'develop a local carbon offset trade market to support local offset projects' [24].

The myPG plan provides numerous initiatives dealing with climate change through both mitigation and adaptation. The plan highlights the importance of integrating climate change considerations in long-range planning processes. Prince George is performing 'very good' in relation to this additional dimension.

\section{DISCUSSION}

The 10 dimensions of sustainable city development, and the additional climate change dimension, are appropriate criteria for evaluating a complex topic such as sustainability. Although not comprehensive - including only transportation, planning, and design elements of community sustainability - the dimensions provide a starting point for evaluating the effectiveness and identifying areas for improvement in urban sustainable development. The exercise is effective in revealing the strengths and weaknesses in the myPG plan and also in the 10 dimensions. Tables 3 and 4 discuss the dimensions in which Prince George is performing well and poorly in, respectively.

One dimension is not included in either table. We decided that the Extensive use of environmental technologies does not fit within either the 'performing well' or 'not performing well' category. There are some interesting activities in this area (e.g. community energy) occurring in Prince George. However, there was not a concerted effort to explore this dimension in the myPG plan, and closedloop infrastructure received only cursory discussion. This may be due to the only recent movement towards closed-loop technologies in cities in general, and in Prince George.

\section{CONCLUSIONS}

Kenworthy's dimensions represent a comprehensive list of urban sustainability principles - including transportation, design, engagement, aesthetic, and equity - for a smaller city in a developed nation. Comparing a community plan to these dimensions provides the following benefits: 
- Clear criteria that cover the breadth of sustainability as it relates to developed regions. This includes many aspects of sustainability that are commonly overlooked in modern definitions and discussion.

- Outcomes directly point towards areas where improvement is necessary.

- An opportunity to showcase areas where rural and northern communities may perform well (such as having natural areas permeate the community), as well as an opportunity to highlight common deficiencies (such as poor transportation networks).

- Inexpensive evaluation that can be undertaken quickly by local experts in partnership with educational institutions.

There are also shortcomings with this exercise:

- Qualitative evaluation may not clearly point towards areas of improvement and can be biased by evaluators.

- Under-resourced communities may not have, or be able to procure, the necessary expertise to properly conduct the evaluations.

- If under-resourced cities and towns can conduct this analysis, these communities may have no avenue to act on the results to make improvements.

Other communities can use these dimensions in the development of core and unique principles guiding planning and implementation efforts towards community and regional-level sustainability. Further research should explore methods to reduce evaluator bias while taking into consideration limited resources in smaller cities, towns, and rural regions. The next challenge is to study the effectiveness of plan implementation. Additional future research opportunities include a large-scale analysis of multiple ICSPs across northern BC (or the entire province) which would reveal the strengths and weaknesses in the plans and, as ICSPs are implemented, explore the effectiveness of these plans in moving communities towards a sustainable future. Outcomes of such an exercise can identify areas of improvement needed in communities and also identify common weaknesses and shortcomings of specific types of plans, policies, or processes. British Columbia and Prince George are taking leadership roles in community sustainability planning. This evaluation has effectively delineated strengths and weaknesses of the Prince George ICSP, and the results can be used to encourage areas where more work is needed.

\section{REFERENCES}

[1] Government of British Columbia, The Integrated Community Sustainability Plan (ICSP) Initiative, available online at http://www.cscd.gov.bc.ca/lgd/intergov_relations/library/ICSP_ Backgrounder.pdf, 2007.

[2] Kenworthy, J., Ten key transport and planning dimensions for sustainable city development. Environment and Urbanization, 18(1), pp. 67-85, 2006. doi: http://dx.doi. org/10.1177/0956247806063947

[3] City of Prince George, available online at http://princegeorge.ca/Pages/default.aspx, 2011.

[4] Llewellyn, J., Understanding a city's form and function: the development and planning history of the city of Prince George, Master's Thesis: University of British Columbia, Submitted December 1999.

[5] Picketts, I., Dyer, D. \& Curry, J., Adaptation to Climate Change in Prince George: An Overview of Adaptation Priorities, City of Prince George: Prince George, BC, 2009. 
[6] Kurz, W., Dymond, C., Stinson, G., Rampley, G. \& Neilson, E., Mountain pine beetle and forest carbon feedback to climate change. Nature, 452, pp. 987-990, 2008. doi: http://dx.doi. org/10.1038/nature06777

[7] Picketts, I., Werner, A., Murdock, T., Curry, J., Déry, S. \& Dyer, D., Planning for climate change adaptation: lessons learned from a community-based workshop. Environmental Science and Policy, 17, pp. 82-93, 2012. doi: http://dx.doi.org/10.1016/j.envsci.2011.12.011

[8] Canadian Institute of Planners, Healthy Communities, available online at http://www.cip-icu. $\mathrm{ca} / \mathrm{web} / \mathrm{la} / \mathrm{en} / \mathrm{pa} / \mathrm{c0aba8d17df149d9bb1ea1bd2d2203e4/template.asp,} 2012$.

[9] United Nations Human Settlements Programme, Planning Sustainable Cities: Global Report on Human Settlements, Earthscan: London, 2009. doi: http://dx.doi.org/ 10.1177/097542531000200111

[10] Rydin, Y., The Purpose of Planning: Creating Sustainable Towns and Cities, The Policy Press: Bristol, UK, 2011. doi: http://dx.doi.org/10.1017/s0047279411000742

[11] Rogerson, R., Sadler, S., Wong, C. \& Green, A., planning sustainable communities - skills and learning to envision future communities. The Town Planning Review, 81(5), pp. 505-21, 2010. doi: http://dx.doi.org/10.3828/tpr.2010.23

[12] Jenks, M. \& Jones, C., Dimensions of the Sustainable City, Springer: London, 2010. doi: http:// dx.doi.org/10.1007/978-1-4020-8647-2

[13] Milbrath, L., Envisioning a Sustainable Society: Learning Our Way Out, State University of New York Press: Albany, New York, 1989. doi: http://dx.doi.org/10.1017/s0376892900033014

[14] United Nations Educational, Scientific and Cultural Organization, The Rio Declaration on Environment and Development, The United Nations Conference on Environment and Development, available online at http://www.unesco.org/pv_obj_cache/pv_obj_id_C0911583226602DD3CE315A0216B9385F1050100/filename/RIO_E.PDF, 1992.

[15] Complete Bellagio Principles, International Institute for Sustainable Development, available online at http://www.iisd.org/measure/principles/progress/bellagio_full.asp, 1996.

[16] Berke, P.R. \& Conroy, M.M., Are we planning for sustainable development? Journal of the American Planning Association, 66(1), pp. 21-22, 2000. doi: http://dx.doi. org/10.1080/01944360008976081

[17] Vancouver Declaration, World Planners Congress, available online at http://integralcity.com/ Ezine\%20Files/WPC2006-Declaration.pdf, 2006.

[18] Reinventing Planning: A New Governance Paradigm for Managing Human Settlements, Position Paper: World Planners Congress, available online at http://www.commonwealthplanners.org/papers/reinvent.pdf, 2006.

[19] Kenworthy, J.R., The eco-city: ten key transport and planning dimensions for sustainable city development. Environment and Urbanization, 18(1), pp. 67-85, 2006. doi: http://dx.doi. org/10.1177/0956247806063947

[20] Yin, R., Case Study Research; Design and Methods, 4th edn., Sage Publications: California, 2009.

[21] Hancock, D.R. \& Algozzine, B., Doing Case Study Research: A Practical Guide for Beginning Researchers, Teachers College Press: New York, 2006. doi: http://dx.doi.org/10.1080/002206 71.2012 .750135

[22] Patton, M., Qualitative Research and Evaluation Methods, 3rd edn., Sage Publication: California, 2002.

[23] Brooks, M.P., Planning Theory for Practitioners, American Planning Association: Chicago, 2002. 
[24] myPG an Integrated Community Sustainability Plan, City of Prince George, available online at http://mypg.ca/about/Documents/myPG_Part_1_web[1].pdf, 2010.

[25] Baker, I., Peterson, A., Brown, G. \& McAlpine, C., Local government response to the impacts of climate change: an evaluation of local climate adaptation plans. Landscape and Urban Planning, 107, pp. 127-135, 2012. doi: http://dx.doi.org/10.1016/j.landurbplan.2012.05.009

[26] Bond, A.J. \& Morrison-Saunders, A., Re-evaluating sustainability assessment: aligning the vision and the practice. Environmental Impact Assessment Review, 31, pp. 1-7, 2011. doi: http://dx.doi.org/10.1016/j.eiar.2010.01.007

[27] Official Community Plan, City of Prince George, available online at http://princegeorge.ca/ citybusiness/longrangeplanning/officialcommunityplan/Documents/ocp.pdf, 2001.

[28] Smart Growth on the Ground (SGOG) Downtown Concept Plan, City of Prince George, available online at http://princegeorge.ca/citybusiness/longrangeplanning/officialcommunityplan/Documents/ocp.pdf, 2001.

[29] Trail System Master Plan, City of Prince George, available online at http://princegeorge.ca/ citybusiness/longrangeplanning/parktrailplans/trailsystemmasterplan/Documents/trailsystem_ masterplan.pdf, 1998.

[30] Active Transportation Plan, City of Prince George, available online at http://princegeorge. $\mathrm{ca} /$ citybusiness/longrangeplanning/transportationplans/activetransportationplan/Documents/ ATP_0_executive_summary.pdf, 2011.

[31] Pressman, N., Northern Cityscape: Linking Design to Climate, Winter Cities Association: Yellowknife, 1995.

[32] Picketts, I., Curry, J., Dery, S. \& Cohen, S., Learning with practitioners: climate change adaptation priorities in a Canadian community. Climatic Change, 188, pp. 321-337, 2013. doi: http://dx.doi.org/10.1007/s10584-012-0653-8

[33] Making Progress on B.C.'s Climate Action Plan, Ministry of Environment, Government of Canada, available online at http://www.env.gov.bc.ca/cas/pdfs/2012-Progress-to-Targets.pdf, 2012. 